\title{
Trabajo de campo en contextos racializados y sexualizados. Cuando la decolonialidad se inscribe en nuestros cuerpos
}

Fieldwork in racialized and sexualized contexts. When decoloniality is embodied in the fieldworkers

\author{
Carmen Gregorio Gil \\ Profesora Titular de Antropología Social. Escuela Universitaria de Trabajo Social. Universidad de Granada (España) \\ carmengg@ugr.es
}

\section{Ana Alcázar Campos \\ Profesora Ayudante Doctora. Departamento de Trabajo Social y Servicios Sociales. Universidad de Granada (España) anaalca@correo.ugr.es}

\author{
CUERPOS, SEXUALIDADES Y PODER \\ MONOGRÁFICO COORDINADO POR JOSÉ MARÍA VALCUENDE. Universidad Pablo de Olavide (Sevilla).
}

\begin{abstract}
RESUMEN
Las autoras, a partir del diálogo que establecen desde sus vivencias en su trabajo de campo en República Dominicana y en Cuba, tratan de adentrarse en los complejos procesos de construcción de la diferencia y del poder. Vivenciar su relación con "los otros" desde su forma de entender la práctica etnográfica las sitúa en ambos contextos como sujetos "deseables", sujetos que abren "posibilidades", incluso "sueños"; haciéndolas tomar conciencia de la racialización y sexualización de sus cuerpos, contenedores de significados que les hablan de la decolonialidad y que les obliga a interrogarse acerca de la reproducción de las relaciones de poder en la práctica etnográfica.
\end{abstract}

ABSTRACT

The authors, based on the dialogue established from their experiences in fieldwork in the Dominican Republic and Cuba, delve into the complex procedures aimed at building both difference and power. Living their relationship with 'the others' from their way of understanding ethnographic practice, place them within both contexts as 'desirable' subjects; subjects that create 'possibilities' even 'dreams'. This makes them aware of the racialization and sexualization of their own bodies, which bear meanings that speak about decoloniality, forcing them to wonder about how to reproduce the power relationships within the ethnographic practice.

PALABRAS CLAVE

etnografía | República Dominicana | Cuba | sexualidad | género | raza | perspectiva feminista | turismo | migraciones | decolonialidad KEYWORDS

ethnography | Dominican Republic | Cuba | sexuality | gender | race | feminist perspective | tourism | migrations | decoloniality

\section{Introducción}

Todo trabajo tiene su historia, su contexto de producción y lógicamente este también lo tiene. Así que vamos a comenzar por ahí, porque sin esa historia no hubiese sido posible llegar hasta aquí, escribir este texto y menos aún hacerlo a dos manos, o si se prefiere a dos voces; voces que dialogan entre ellas, interrogándose y desafiándose, compartiendo contradicciones y temores vividos en el oficio de hacer (y vivir) etnografía, de re-habitar nuestras primeras etnografías, en contextos similares o más bien percibidos en su similitud desde las propias vivencias de cada una de nosotras como antropólogas "mujeres", "jóvenes", "españolas", "blancas" y por todo ello "deseables", en Cuba en el caso de Ana (1) y en la región suroeste de República Dominicana en el caso de Carmen (2).

Ana y yo comenzamos a pensar juntas en el marco de la asignatura "Prácticas de trabajo de campo" en el curso 2001/02 de la Licenciatura de Antropología Social en la Universidad de Granada. Yo había sido profesora de Ana en la asignatura de "Antropología del género" dos años antes y en este contexto conocía mis trabajos sobre género e inmigración. Ana tenía una larga experiencia en el trabajo con mujeres víctimas de violencia de género y como activista en diferentes grupos de mujeres, por lo que la opción de que yo le tutelase esta asignatura en la que se proponía hacer un trabajo sobre mujeres inmigrantes en el servicio doméstico en la ciudad de Granada venía casi dada (3). Más tarde Ana se matriculó en el programa de 
doctorado en el departamento de Antropología Social y Trabajo Social (4) y me propuso dirigirle su tesis doctoral. Ana quería trabajar en Cuba sobre la construcción de desigualdades, especialmente las de género, conocer mi trabajo de campo etnográfico en República Dominicana y compartir nuestras preocupaciones teóricas y políticas sobre los procesos de construcción de la desigualdad de nuevo me presentaba como la opción más afín. El proceso de realización de la tesis doctoral y el proyecto de investigación sobre "Mujeres en el servicio doméstico en la ciudad de Granada" (5) fue una oportunidad para compartir nuestras interpretaciones sobre los procesos de construcción de las desigualdades de género, etnicidad, extranjería, raza, así como no pocas reflexiones del propio proceso de trabajo de campo etnográfico. Mis preguntas a Carmen acerca de la validez de los datos, de la utilidad de la investigación para las personas con quienes trabajábamos, así como de las relaciones de poder en el trabajo de campo, nos fueron llevando, desde una perspectiva feminista, a lugares comunes. Aún recuerdo la primera comunicación que escribí (6), a instancias de Carmen, y cómo, en el primer borrador que le enseñé, en vez de utilizar las voces de las mujeres producidas en el trabajo de campo, me había empeñado en hacer una revisión teórica del tema, incompleta e innecesaria, desde la que interpretar a las mujeres. No se me olvida cómo Carmen dio importancia a una forma de entender la antropología y la metodología etnográfica.

Con el discurrir del tiempo, las personas "sujetos" de nuestras investigaciones y la realidad compartida con ellas no sólo fue comprometiendo la cotidianidad de cada una de nosotras, también nuestra propia relación como maestra y discípula. Ésta se fue tornando en una relación entre colegas antropólogas y amigas que nos llevó a contarnos aquello que no habíamos contado cuando escribimos los resultados de nuestros trabajos de campo etnográficos. Todo aquello que habitualmente no se cuenta, porque nos puede dejar en "un mal lugar" al confesar, por ejemplo, que nos hemos saltado supuestas prohibiciones porque transgrede tabúes sobre las prácticas sexuales en el campo, o porque destapa sentimientos que no desearíamos tener o que nos confrontan con nuestros valores. En definitiva, cuestiones que toman relación con nuestras responsabilidades éticas pero en las que están fuertemente contenidas, pero también acalladas, las dimensiones afectivas implicadas en nuestra relación con las personas con las que convivimos en el campo, con los positivistamente llamados sujetos de estudio.

Desde los presupuestos epistemológicos dominantes, los resultados de nuestros trabajos de campo, para ser considerados cientíicos, habían de estar guiados por la doctrina de la "inmaculada percepción" (Van Maanen 1988: 73), despojados de las "manchas subjetivas" de todo lo experiencial en el encuentro con "el otro", en pos de la búsqueda del rigor metodológico (Bell 1993) y de la disminución de los llamados "sesgos personales". En resumidas cuentas, el investigador en su búsqueda de la anhelada "objetividad" habría de comportarse y aparecer, como plantea Nancy Scheper-Hughes (1983) y es recogido en Gregorio Gil (2006: 31 ), como un muñeco de nieve observando de modo penetrante, pero invisible en su acción y frío en sus afectos y pasiones, y por supuesto, enfatizamos nosotras, asexual.

Las contribuciones de la etnografía feminista (7) han sido reveladoras en cada una de nosotras para repensar la forma en la que escribimos los resultados de nuestras investigaciones, desde el reconocimiento del carácter parcial y situado del conocimiento científico que planteara Haraway (1991), pero también como forma de restituir el valor del saber vivencial (8), implicado y comprometido (9). Saber desde el que la razón y la emoción no sean dos polos distinguibles y contrapuestos como el pensamiento occidental androcéntrico y etnocéntrico nos quiere hacer creer, sobredimensionando el valor de lo "racional" frente a lo "emocional", lo científico frente a lo no científico y en el fondo lo masculino, en su asociación aristotélica con la razón, frente a lo femenino en su asociación con lo emocional. Y es desde este nuevo lugar epistemológico desde el que estamos tratando de generar, juntas, espacios de reflexión, y desde el que pretendemos aportar nuestro granito de arena al proyecto de investigación LIESS en el que se inscribe este artículo (10).

\section{Habitar nuestras etnografías}

En este apartado nos adentraremos en los complejos procesos de construcción de la diferencia y el poder, a partir del diálogo que vamos a establecer desde nuestras vivencias en el trabajo de campo etnográfico realizado en el contexto de las migraciones originadas en el suroeste de República Dominicana a finales de los ochenta y principios del año 1990, en el caso de Carmen, y en el contexto del turismo internacional de masas introducido en el oriente cubano a finales de los noventa y principios del año 2000 , en el caso de Ana. 
Traeremos aquí algunas de las experiencias vividas durante nuestros respectivos trabajos de campo, sacándolas del espacio de "intimidad" en el que las veníamos compartiendo como amigas, para convertirlas en objeto de indagación, de teorización, entendiendo con Okely (1975 y 1992) que lo personal no sólo es político, como bien se ha encargado de aclamar el feminismo, sino también teórico (Gregorio 2006: 32). Como diría nuestra colega Jone Miren Hernández intentamos "habitar" en nuestras propias etnografías para entenderlas "como experiencia de la antropóloga relacionada con actitudes culturales presentes en la sociedad y no como expresión 'del conocimiento' abstracto, impersonal, descontextualizado" (Hernández 2012: 1), y en este sentido lo hacemos con la intención de restituir el valor del conocimiento desde nuestros propios cuerpos como sujetos de acción que experimentan, sienten, se emocionan.

Desde nuestra preocupación compartida por la teorización sobre las articulaciones entre diferenciaciones sociohistóricas de género, raza, sexualidad e inmigración en la construcción de la desigualdad (11), convertiremos nuestras vivencias en la relación con los "otros" en objeto de indagación y exploración de las diferenciaciones sociales inscritas en los cuerpos. Entendiendo la reflexividad como aquello que "it makes a problem out of what was once unproblematic: the figure of the fieldworker" (Strathern 1991: 8) trataremos de explorar los significados codificados de nuestro ser en el proceso de interacción en el campo. Todo ello situándolo en dos contextos etnográficos, Cuba y República Dominicana, que compartieron un sistema colonial esclavista en el que la raza, el género y la sexualidad fueron criterios de diferenciación y jerarquización social mediante los que, en sus diferentes combinaciones y articulaciones, fue naturalizada la desigualdad social. En el contexto actual de globalización, el desarrollo del turismo de masas a partir de los años sesenta, coincidiendo con la implantación de los Estados de Bienestar europeos y la consolidación de la economía norteamericana, convierte a Cuba y a República Dominicana en "sitios de deseo" (Manderson y Jolly 1997) al tiempo que en la década de los noventa y la primera década del siglo XXI un desarrollo económico basado en la construcción, la agricultura intensiva y el sector servicios, especialmente los servicios domésticos y de cuidados (12) convierten al estado español en "sitio de posibilidad", de "exilio económico" para los ciudadanos y ciudadanas cubanas y dominicanas de los sectores sociales más desfavorecidos.

\section{1. "Mejorar la raza" y "adelantar la raza": trabajo de campo en contextos racializados}

A partir de las situaciones que hemos enfrentado en la realización de nuestros respectivos trabajos de campo hablamos de "contextos etnográficos racializados". Conocedoras del pasado colonial de Cuba y de República Dominicana y de la ideología racista de la "pureza de sangre" (Stolcke 1992), mantenedora de un sistema esclavista de Plantación hasta finales del siglo XIX (13), ninguna de las dos podíamos sospechar, ni tan siquiera imaginar, cómo nuestra relación con las personas en nuestro trabajo de campo estaría atravesada por la racialización de nuestros cuerpos. Cómo la construcción del "nosotras" a partir del "otro" estaría marcada por diferenciaciones de raza, sexualidad, género e historia colonial.

En Cuba, la raza, entendida como un criterio de diferenciación social construido, no sólo es utilizada para jerarquizar y clasificar a la población en un complejo sistema de estratificación, sino que ha sido incorporada en los procesos de construcción nacional. Esto se lleva a cabo a través de la nacionalización de ciertos aspectos de la cultura afrocubana a finales de los años veinte y durante la década de los años treinta del siglo XX (Moore 1997). Aspecto retomado, a mediados de los años cuarenta del siglo XX, por Fernando Ortiz (2010) cuando utiliza la metáfora del ajiaco cubano como definidor de la cubanía. Según la misma, lo cubano está compuesto por todas las herencias de las que Cuba es deudora que son puestas a rebullir, cual ajiaco, creando la identidad nacional cubana, una identidad que no privilegia ningún componente, donde "el que no tiene de congo, tiene de carabali" (14), reforzando también la tesis de la unidad nacional que formulara Martí. No obstante, lo que yo experimenté era que el componente afrocubano, supuestamente diluido en ese ajiaco, en algunas circunstancias era desvalorizado y rechazado. Así, en mis conversaciones me llamaba mucho la atención cuando se filtraban expresiones que yo había leído en el libro de Verena Stolcke (1992) sobre la configuración racial en la Cuba esclavista, y creía que pertenecían a tiempos pretéritos. En concreto, me refiero a la expresión: "adelantar la raza", usada para connotar positivamente relaciones de pareja entre hombres negros o mulatos y mujeres blancas. Algo que viví en primera persona al establecer una relación de pareja con uno de mis amigos allí, Adrián, auto y hetero definido como mulato, y oír cómo esa expresión, en tono jocoso, aparecía en los comentarios que sus amigos hacían sobre "lo nuestro". Su centralidad, para él, se puso de manifiesto un día, hablando sobre nuestras parejas anteriores, ya que Adrián me dijo que siempre había estado con mujeres más claras que él: "Mima (15), yo siempre he estado con mujeres más claras y no es tanto el color como el pelo. Yo meter 
así los dedos (me acaricia el pelo a modo de peine) y que no pasen los dedos..., es que no puedo. No soporto el pelo malo" (Diario de campo, marzo de 2005).

Vivencias como esta hicieron que me sintiese "blanca", pero también en otras ocasiones, observando cómo lo blanco y lo negro era usado en el discurso para afirmar diferentes aspectos identitarios, mi cuerpo terminaba fluyendo entre lo blanco y lo negro, específicamente en Santiago de Cuba (16). Durante las diferentes estancias de investigación que hice, en mis viajes a La Habana era "la santiaguera" y siempre acababa envuelta en discusiones reivindicando Santiago y denunciando actitudes racistas en la denominación de "palestinos" a la población santiaguera (rural, negra, pobre). Cuando estaba en Santiago, sin embargo, en algunas conversaciones se esgrimía la negritud con orgullo reivindicando al General Maceo, héroe de la Guerra de Independencia española, santiaguero y negro, aunque, de manera contradictoria, se resaltaba también cómo la Revolución había posibilitado, mediante la adquisición de "cultura", huir de ciertos elementos identificados como de "baja estofa", irremediablemente calificados como negros. Esta construcción de "lo negro" era acompañada de la construcción de "lo blanco". En mi vivencia como "blanca" sentí una serie de exigencias que se filtraban en las conversaciones, como una vez en la que Adela, la dueña de la casa en la que permanecí ocho meses, madre de Adrián, y con la que creé una relación de complicidad e intimidad, tras contarle mi nefasto día de compras, acompañado de una bronca con una dependienta, terminaba afirmando: "M'hija, jte salió el negro!, jtú eres blanca de casualidad!". Esta expresión no era nueva para mí ya que la había oído en ocasiones anteriores en las que, por ejemplo, reía de forma ostensible o no me vestía con el suficiente "decoro".

En este contexto yo sentía que algunos requerimientos, como tener paciencia, vestir con decoro o ser suave y hablar en voz baja se dirigían hacia mí por mi blanquitud. Así, debía circular por identidades que eran definidas idealmente como polarizadas (blanco/negro) con una serie de elementos que también me definían en tanto que mujer, intersectando los procesos de racialización con los de generización y extranjerización. Identidades que, no obstante, no eran fijas, dándose un proceso de construcción racial fluido y modificable por elementos como la educación, la clase, el refinamiento o lo que se denomina "cultura". Algo que yo sentía que era defendido por quienes se relacionaban conmigo como un logro de la Revolución y que hacía que la cuestión de la raza se mantuviera oculto, en tanto que algo "superado" por el proceso revolucionario.

En República Dominicana el color de piel constituye igualmente un criterio de diferenciación social; por ejemplo, las personas en sus documentos de identidad son clasificadas en función de diferentes tonalidades de su piel (india clara, trigueña, prieta, mulata, negra, etc.). La raza como categoría social impregna la estructura fuertemente estratificada de la sociedad dominicana. No hay que ser muy aguda para observar cómo, a pesar de la diversidad de tonalidades de piel de la población dominicana, en las regiones del país más empobrecidas o en los suburbios de las ciudades la población es mayoritariamente de piel oscura. La región donde realicé mi trabajo de campo muy cercana a la frontera con Haití es mayoritariamente "negra". Por el contrario en los espacios a los que sólo tienen acceso las clases sociales más adineradas la gente llamativamente es "blanca". Una de las expresiones más extremas de racismo hacia el haitiano, que en República Dominicana se emplea como sinónimo de "negro", son los lugares denominados bateyes (17) en los que se explota la caña de azúcar en un régimen calificado de esclavitud por diferentes organizaciones de Derechos Humanos. La piel negra en su asociación con lo "afrodescendiente" y lo "haitiano" es motivo de desvalorización, rechazo y repulsa que se expresa, tanto en las relaciones cotidianas como en las políticas eugenésicas, en mayor o menor grado, que han venido practicando los diferentes gobiernos en la época contemporánea. Desde las políticas denominadas de "blanqueamiento de la raza" durante la dictadura de Trujillo, hasta la reciente actuación del Tribunal Constitucional dominicano denunciada por la Corte Interamericana de Derechos Humanos mediante la que se despoja de su nacionalidad a decenas de miles de dominicanos y dominicanas hijos o descendientes de ciudadanos haitianos, a pesar de haber nacido en el territorio nacional antes de la entrada en vigencia de la Constitución del año 2010 (18).

El rechazo hacia lo negro fue algo que observé en las relaciones cotidianas en las comunidades de la región suroeste donde realicé mi trabajo de campo. Para describir lo bello la gama de colores siempre era blanca, clara...; por el contrario, para mostrar disgusto o fealdad se utilizaba el término "prieto", "negro" y "haitiano". Fue algo que también experimenté desde los significados que iba cobrando mi cuerpo en las más diversas situaciones en las que nos coloca la metodología etnográfica.

Estaba familiarizada, al tiempo que indignada, con los relatos de discriminación por el color de su piel que me compartían las mujeres dominicanas en Madrid cuando me hablaban del trato que recibían de sus 
empleadores o de los pequeños a quienes cuidaban, así como de los y las vecinas de Aravaca (19). Mi convivencia con ellas hacía que me sintiese "española" dada mi posición de ciudadana con derechos plenos, aunque que yo para ellas era una "española diferente" como oía con frecuencia: "Carmen no parece española". Sin embargo, nunca me sentí "blanca" como me sentiría meses después cuando viajé a sus comunidades de origen en República Dominicana y viviera en mi propia piel los significados que puede atribuírsele al color de la piel.

En mi trabajo de campo, nunca llegué a pasar desapercibida. Sentía que en mi relación con los "otros" ocupaba una posición de deseabilidad difícil de obviar. Cuando paseaba por las calles los hombres se quedaban mirándome haciendo alusiones continuas a mi "belleza", sin mostrar ningún problema en proponerme relaciones sexuales. Yo trataba de masculinizar mi cuerpo utilizando ropas anchas y no llevando maquillaje, no tanto para pasar desapercibida como antropóloga sino como "mujer", pero aún así no conseguía disminuir las invitaciones sexuales que no dejaban de incomodarme. Fui comprendiendo, a medida que fui relacionándome con las personas y en un contexto amplio de situaciones, que la atracción la producía una combinación de significados de "blancura" y "españolidad", y por su puesto el hecho de caminar por la calle en un contexto en el que el "hombre es de la calle y la mujer de la casa" (Gregorio 1998), por lo que una mujer que camina sola por la calle es considerada una "mujer pública" en el sentido de disponible sexualmente. Cuando caminaba en solitario los comentarios se dirigían hacia mí. Si iba acompañada de un hombre dominicano, el resto silenciaba sus miradas o sus comentarios se dirigían a él para alabar su suerte de ir en mi compañía. Cuando iba con una mujer dominicana, era ella la interpelada, reclamándole que se acercase para que presentase a la española que iba con ella. En Aravaca, la plaza pública en la que venía realizando mi trabajo de campo en Madrid, por la que también caminaba sola o acompañada de otras mujeres dominicanas nunca había experimentado tales sensaciones. En el contexto altamente feminizado de esta plaza los hombres dominicanos o estaban con sus esposas, lo que les impediría cortejar a otras mujeres al menos delante de ellas, o se dedicaban a actividades dentro de la economía sumergida, por lo que mi identificación como mujer española, les causaba más desconfianza que cualquier otra cosa.

Desde la cercanía que establecí con algunos hombres y mujeres pude saber que mi cuerpo no respondía precisamente al prototipo de belleza sexual y la atracción la producía la blancura de mi piel. Las mujeres y hombres españoles parecíamos a los y las dominicanas "fríos" sexualmente, por contraste ellos y ellas se definían como "calientes". El poco atractivo sexual en los hombres se representaba con los calzoncillos largos que decían que usaban las mujeres que habían emigrado. En algunas de mis conversaciones los hombres hablaban con lascivia de los cuerpos voluminosos de las mujeres, asociándose sin embargo la delgadez a enfermedad o mala alimentación, yo les habría de parecer enferma porque para entonces estaba bastante delgada. Por tanto, todo parecía indicar que era mi piel "blanca" la que ejercía tal atracción. Me sentía una mujer blanca cuando los hombres me piropeaban, pero también cuando las más pequeñas acariciaban mi pelo fascinadas mientras decían "¡Qué pelo bueno tiene Carmen!”. "Pero ¿por qué me decís eso?", yo les preguntaba, "a mí me encanta vuestro pelo, siempre he querido tener el pelo rizado como vosotras", a lo que ellas me respondían "iNo!, el nuestro es malo, duro". Los moñitos con los que siempre iban peinadas las niñas dejaron de parecerme tan simpáticos en cuanto reparé en el ejercicio de doma y castigo del cuerpo de las mujeres que suponían y cuando fui consciente de la encarnación en éstos de la historia colonial. En mi trabajo de campo experimenté en muchas ocasiones los privilegios de ser blanca, algo a lo que trataba de resistirme, aunque sirviese de poco. Por ejemplo, el comentario de una mujer dominicana asentada en Madrid e investigadora de clase media-alta y con la que compartí unos días de estancia en la capital de República Dominicana, Santo Domingo, fue muy revelador por la carga de denuncia y rabia con la que se expresaba: "Vosotras las blanquitas podéis vestir como queráis, nadie os va a impedir la entrada a ningún lugar por ello". Efectivamente, así lo experimenté: ser blanca, y añadiría española, era una "carta blanca" para relacionarme y participar en diferentes espacios en República Dominicana que están vetados a la gente de piel negra y a las mujeres dominicanas. Pude vivir la relevancia que se le da a la posibilidad de "blanquear la raza" al momento de elegir una pareja para procrear. Mi propio cuerpo era deseado como cuerpo reproductor. Recuerdo como con un hombre con quién tuve una relación muy cercana le gustaba imaginarse lo bonitos que serían nuestros hijos al aclarárseles la piel.

Así de orgullosa por ejemplo me mostraba la abuela a su nieto blanquito, al que llamaban el españolito: 


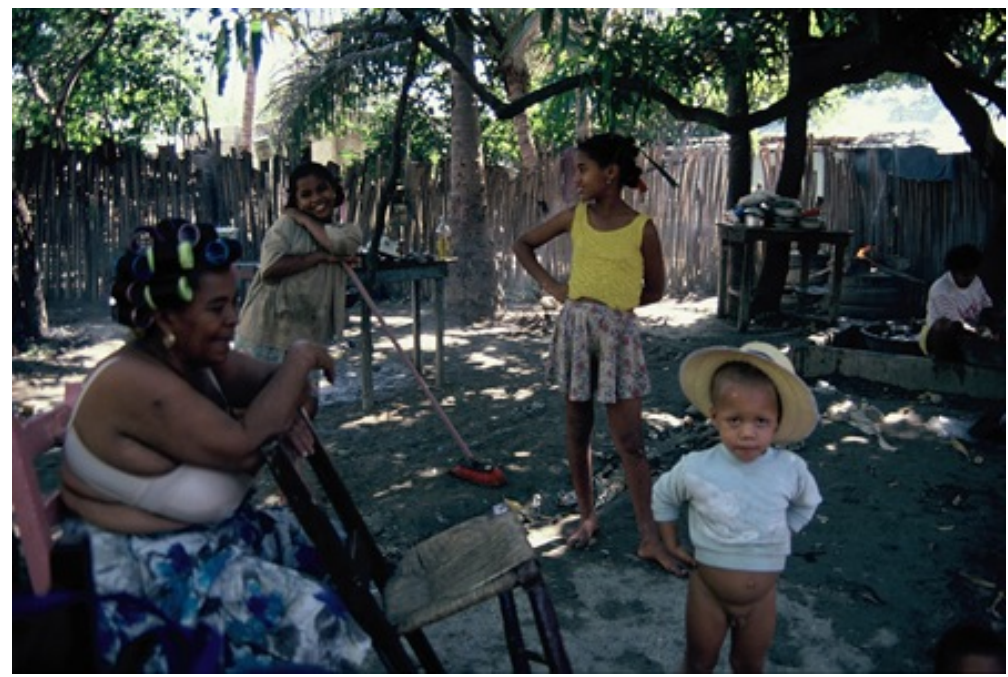

"Abuela con sus nietos en el patio de una casa en Vicente Noble". Foto: Carmen Gregorio Gil, enero 1995

A la blancura se unían otros significados de españolidad, incluso de añoranza por la "madre patria" que me situaban en una posición privilegiada y que no hacía sino hablarme de la dominación colonial largamente ejercida en este país. Mi manera de hablar se describía como "fina", "biensonante", frente a la suya que era "dura". Cuando me hablaban de las mujeres inmigrantes me decían que venían españolizadas porque venían hablando "fino", algo que efectivamente observaba en la forma de hablar de muchas mujeres que forzaban su entonación marcando eses donde no existen en castellano. Otras mujeres inmigrantes, concienciadas de que su forma de hablar podría marcar la distancia social e incluso ofender a sus paisanos, me expresaban que trataban de evitar hablar como españolas.

En definitiva, en ambos contextos observamos a partir de nuestras vivencias en el campo cómo la categoría raza se expresa en ideologías eugenésicas y tecnologías disciplinarias (Foucault 1978) que se encarnan en los cuerpos de las mujeres. Ideologías y prácticas que a pesar de las diferencias al respecto de la representación racial de la nación cubana y dominicana, sin duda, remiten a un pasado colonial compartido como nos recuerda la activista afroamericana bell hooks "nuestra obsesión colectiva con alisar el cabello negro refleja la psicología de opresión y el impacto de la colonización racista" (2005: 11).

\subsection{Españolas: cuando las remesas y el turismo nos convierten en personas deseadas}

Nuestra procedencia española y europea estuvo siempre presente en nuestra relación con los "otros". Sentíamos que ello nos situaba frente a los demás como personas deseadas en tanto que podíamos posibilitar la movilidad social ascendente, bien dentro del propio país o facilitando la salida del mismo. Nuestros cuerpos representaban ese país del que llegaban las remesas de las emigrantes (España) y al que en ese momento casi todo el mundo deseaba ir, y ese país del que procedían los turistas con euros y capital social y donde residían gran cantidad de compatriotas que, en sus visitas a sus países de origen, ejemplificaban el deseado ascenso social.

En mis paseos por Santiago y La Habana siempre me identificaban como española. Los chicos que estaban en la calle, en el casco histórico, buscándose la vida con los y las turistas me decían: "Tía, tía", "Zapatero, Zapatero" como una forma de entablar conversación e intentar "jinetear". Neologismo que empezó a formar parte de mi vocabulario cubano desde mi primer viaje, definiendo toda actividad vinculada con el turismo dirigida a obtener un beneficio del mismo, y que me trajo no pocos quebraderos de cabeza... Pongamos, antes, un poco de contexto. En Cuba, tras la caída del bloque socialista se inicia el Periodo Especial en Tiempos de Paz, donde se acometen diferentes reformas que buscan insertar a Cuba en la corriente principal de la economía internacional. Entre estas reformas destacan la liberalización del dólar en 1994, creándose una doble economía desde esa fecha, con una moneda que vale 24 veces más que el peso cubano y que es necesaria para adquirir ciertos productos; y la promoción del turismo internacional de masas vinculándose, simbólicamente, con la situación pre-revolucionaria, donde el turismo era uno de los sectores económicos clave y del que se denunciaba que generaba dependencia de los EE.UU., al ser éstos el principal país emisor de turistas hacia Cuba (20). En Santiago de Cuba y en La Habana, dos lugares con 
una clara afluencia de turismo, las referencias a mi nacionalidad utilizadas para conectar conmigo construían España como un lugar de deseo, y yo representaba, por mi extranjería, también un sujeto deseado al posibilitar una movilidad ascendente más allá de los mecanismos previstos por el Estado (a través del viaje fuera del país pero también dentro de la estructura social cubana).

Esto se puso bastante en evidencia durante mi última estancia de investigación, en 2009, cuando contacté con varios investigadores de la Universidad de La Habana, los cuales no dejaban de proponerme colaboraciones, muchas de ellas sin aparente sentido para mí, que, inmediatamente, se frustraban al saber mi débil posición en mi Universidad. Expresiones como "Estoy loco por ir a España" o referencias a "la madre patria" y al deseo de conocer el lugar de origen de los antepasados españoles venían a reforzar argumentos pretendidamente académicos. Estas propuestas junto con otras para contraer matrimonios de conveniencia, camuflados de amor "real" o no, no dejaban de hablarme de esa deseabilidad en tanto que española.

Así mismo, mi extranjería era funcional en el contexto: en múltiples ocasiones compré medicamentos en la farmacia internacional, abrí cuentas de correo electrónico, consulté cuentas existentes, cambié divisas, di acceso a hoteles, compré un móvil, hice una carta de invitación, etc. etc. Favores que me eran demandados, en la mayoría de las ocasiones, por los que yo, obviamente, no pedía dinero a cambio. En algunas ocasiones percibía que la gente me pedía favores por mi condición de extranjera, como en los ejemplos citados, pero en otros casos la demanda estaba asociada también a mi poder adquisitivo, generándome una incómoda sensación de "ser un dólar andante". Esto me provocaba sentimientos contradictorios. Por un lado, entendía que esos favores entraban dentro de las relaciones de reciprocidad, sobre todo teniendo en cuenta que la doble economía a la que me refería antes condiciona que determinados productos, como los de higiene personal, tengan que ser adquiridos en una moneda en paridad con el dólar, el CUC, en la que no se devengan los salarios o, en el mejor de los casos, tan sólo una parte de los mismos. Pero, por otro lado, quería ser yo quién eligiera con quién/es establecer relaciones de reciprocidad, creándose situaciones incómodas en las que "se daba por hecho" que yo asumía el coste, por ejemplo, de una comida en un restaurante. Estas contradicciones se vieron agravadas por la regulación del "jineterismo" que hay en Cuba... Ubicado dentro de la legislación existente en torno a la "peligrosidad social", un cubano/a puede ser acusado de "acoso al turista" y ser calificado de jinetero/a, levantándosele una carta de advertencia. La acumulación de tres de éstas puede implicar el paso por un "centro de reeducación" para las mujeres (al entender que están ejerciendo la prostitución) y por la cárcel, para los varones, si se trata de delitos relacionados con la economía informal (venta ilegal de productos, transporte ilegal de personas, etc.) (21). Esta regulación estuvo presente en mis relaciones al tiempo que reforzaba la representación social del carácter interesado de la relación del cubano y cubana con el extranjero.

En mi caso, no dejaba de sorprenderme y molestarme la sempiterna "palabrita" que se hacía presente aún en las circunstancias más peregrinas, como cuando un día llegué a casa de Liudmila, una amiga cubana, y ésta, al ver que su perro me saludaba moviendo el rabo, comentó: “¡Vaya un perro jinetero!”. Así mismo, las continuas dificultades que experimenté para llevar a cabo acciones tan comunes como comprar comida, que siempre me querían cobrar en CUC, o inscribirme en un gimnasio, derivándome siempre al de los extranjeros, también en CUC, me hacían sentir como una fuente de recursos. Elemento este que también era reforzado por quienes estaban más cercanos a mí como una forma de diferenciarse y de desvincular su relación del interés. Tal y como me dijo un día Adela: "M`hija, aquí en Cuba todo lo que tiene que ver con ustedes, con los extranjeros, es jineteo".

Esto condicionaba que relaciones que debían, a mi modo de ver, ser "desinteresadas" como los ejercicios de seducción, las amistades, los cuidados, etc. fueran puestas en tela de juicio por mí ante la sospecha de jineterismo. Esto no dejaba de crearme angustia ya que, por un lado, no quería reproducir relaciones de poder, creando situaciones que yo entendía como nuevas formas de dominación colonial que veía en otros compatriotas turistas que visitaban la isla. Por otro, me sentía vinculada emocional y afectivamente con determinadas personas y no me gustaba sentir que "estaban conmigo por el interés", al tiempo que me preocupaba que pudieran tener problemas por andar conmigo y ser acusados de jineterismo. No fue hasta mi regreso que, con la distancia necesaria, comprendí que todos y todas tenemos intereses y que, en todas las relaciones intervienen muchos aspectos, económicos, emocionales, de creación de redes, etc., y por eso no son menos "auténticas".

Una mujer joven, blanca y española paseando sola por las calles de Vicente Noble, Tamayo o Azua en 
República Dominicana, era algo poco común; además, el que proviniese del lugar del que llegaban las remesas me convertía en alguien deseable y para los hombres en una posible candidata a seducir, pero sobre todo en un posible contacto para posibilitar la emigración a España o proporcionar algunos dólares siempre bienvenidos en una economía rural de subsistencia que ofrece pocas posibilidades para acumular capital y poseer los bienes de una sociedad de consumo.

En una de las poblaciones en donde realicé el trabajo de campo, un día conversando con una mujer me compartió que se rumoreaba que yo era la española que la mujer inmigrante, en cuya casa me alojaba, había enviado para que me casase con su hijo. Me quedé estupefacta, él tenía entonces 15 años y yo le doblaba prácticamente la edad, lo consideraba como mi hermano, pues su madre y su padre me consideraban como su hija, pero es cierto que su deseo de ir a España estaba siempre presente en sus conversaciones conmigo; quería que su madre lo llevase a España, por lo que nunca pensé que la posibilidad de ir a España se la plantease a partir de su matrimonio conmigo.

El impacto de la emigración a España en las comunidades donde realicé el trabajo de campo era tal que el sólo hecho de mi presencia se relacionaba automáticamente con la "madre patria", ahora convertida en receptora de mujeres inmigrantes. Recuerdo que uno de mis primeros días en el pueblo de Tamayo, cuando paseaba por la calle, una mujer que iba montada en una bicicleta me gritó sin bajarse de la bici y sin que yo cruzase ni una sola palabra con ella: "Yo fui dos veces a España y me devolvieron". Hechos como estos se repetían con frecuencia. Mi presencia, simbolizaba el nexo de unión entre las personas migrantes y sus familiares. Así, por ejemplo, un día un hombre que iba borracho por la calle quejándose de su esposa que estaba en España, en un determinando momento se dirigió a mí y me espetó: "Yo estoy así por ella, cuando vuelva la voy a matar, yo tomo ron por ella", creyendo quizás que yo le haría llegar este comentario a su esposa. Otro día, mientras conversaba con un grupo de personas comenzaron a hablar de un hombre que tenía a varios familiares en España para censurarle: "¡Estando tú aquí y no han venido ni a preguntar por ellas!". Veinte años más tarde,(22) mientras cogía el autobús que me llevaría a Vicente Noble en Santo Domingo, uno de los vendedores que entraban en los autobuses nada más verme empezó a decirme "Tía, joder", imitaba un argot que rápidamente identifique como madrileño.

En una economía de subsistencia, donde las remesas no siempre llegaban a los más necesitados, en la que las relaciones de reciprocidad son muy importantes para la reproducción de los hogares y, por tanto, en la que cada día había que invocar a los dioses, como hacía Santica, para que apareciese algo que comer, las peticiones de dinero hacía mí, "a la española", eran constantes. Las demandas se expresaban en la cotidianidad compartida, mi presencia podía aligerar las cargas económicas derivadas de la alimentación, vestido, saneamiento y salud del grupo doméstico, pero también permitían a hombres y mujeres disfrutar de cierta movilidad si yo me hacía cargo del pago del transporte o de pasar un buen rato compartiendo un trago de ron o cerveza. Yo solía hacer mis contribuciones, pues no dejaba de tener presente que me estaban acompañando para que yo realizase mi trabajo de campo, por lo que lo vivía como una forma de reciprocidad. Si bien, cuidaba de no contribuir a reforzar la imagen de la "española rica" como sentía que todo el mundo parecía verme a pesar de haber viajado con mi precario sueldo de becaria de investigación. Para ello trataba de evitar, quizás demasiado ingenuamente, alimentar relaciones basadas únicamente en aportación económica de mi parte; por ejemplo, para mí no era lo mismo mi aportación económica con quiénes compartía mi cotidianidad que con quiénes no la había, o aportar dinero para la comida que para comprar ron, o pagar por lavar mi ropa después de que me lo pidiesen y yo tratase de resistirme explicando que yo debía ser quién la lavase. Me debatía continuamente tratando de valorar para qué, en qué momento, qué cantidad y a quién. El corazón se me sigue encogiendo cuando rememoro como Santica, con su enajenación mental consecuencia de haber sufrido varios ictus cerebrales, las primeras palabras que pronunció al verme veinte años después, como si hubiese sido una aparición divina, me miró fijamente a los ojos y me dijo: "no tengo medicinas". Sus nietos y biznietos sorprendidos de que me hablase le preguntaron: "Pero ¿la conoce mae?”, a lo que ella respondió pausadamente: “¡Y, claro, Carmen, la española!".

En ambos contextos, el origen de la antropóloga no es un lugar ajeno para las personas con las que se relaciona en el trabajo de campo, sino un lugar que en el orden económico y geopolítico internacional es representado como un lugar de deseo, de oportunidades, de emigración para encontrar una vida mejor, un lugar en el que hay riqueza. Ello nos coloca en una relación de poder frente a quienes nos demandan nuestro capital social y económico que nos interroga continuamente sobre nuestras prácticas para evitar reproducir relaciones de poder. Al tiempo, nos coloca también en un lugar de incomodidad al no querer reforzar la idea del "europeo rico", incluso de vulnerabilidad al sentir el carácter instrumental e interesado de la relación que 
"el otro" mantiene con nosotras, pero ¿no es igualmente instrumental nuestra relación con ellos y ellas en el fondo como cualquier otra relación humana?, ¿por qué nos incomoda tanto esta demanda material? Nuestra incomodidad es producto de una relación en la que sentimos el peso ineludible de nuestra responsabilidad para con el otro como sujetos históricos, al tiempo que el deseo y la impotencia para contribuir a establecer órdenes de relaciones más igualitarios.

\subsection{La modernidad colonial: género, raza y sexualidad}

En la identificación que venimos haciendo de criterios que estructuran nuestras relaciones como antropólogas en las llamadas "zonas de contacto" por Pratt (1992) (23), no queremos dejar de referirnos al discurso de la modernidad colonial, enunciada por autores como Mignolo (2000) y Quijano (1997), en el que se articulan el género, la sexualidad y la raza. Ambos autores ponen de manifiesto la emergencia del hemisferio occidental y la inclusión conflictiva de los territorios americanos en el mismo y, por extensión, en la modernidad de la que forma parte indisoluble la colonialidad (Mignolo 2009) y que se manifiesta, entre otras cuestiones, en una oposición "tradicional versus liberal o moderno". Dentro de esta concepción colonial, el origen nacional intersecta con la categoría mujer, donde la construcción de la sexualidad se reinterpreta en un contexto de relaciones históricas coloniales que configuran lo que Lugones (2008: 77) denomina "el sistema moderno-colonial de género". Para esta autora, este cuenta con un lado oculto/oscuro y con un lado visible/claro que clasifica a las mujeres tras el "encuentro colonial". En el primero se situarían las mujeres clasificadas como negras, "promiscuas, animalizadas y destinadas al trabajo". En el segundo estarían las mujeres blancas burguesas "puras, pasivas sexualmente y reproductoras de la clase y posición social y racial de los hombres blancos". Destacando también la emergencia de "una zona gris" donde se situarían las mujeres blancas trabajadoras, no burguesas, "como seres que no pueden ser captados por los lentes del binario sexual o de género y que, a la vez, son racializados de forma ambigua pero ya no como blancos o negros" (Lugones 2008: 41).

La vigencia de este discurso la hemos vivido en nuestra experiencia etnográfica en diversas situaciones al proyectarse sobre nosotras la imagen de "mujeres occidentales modernas", liberadas sexualmente del yugo del esposo, por un lado; y por otro, encarnando una sexualidad libre pero "modernizada", más contenida, domada o controlada y contrapuesta a una sexualidad animalizada, corporalizada e irreprimible.

En mis vivencias en Cuba, reflejadas en mi diario de campo, uno de los temas recurrentes era el sexo. Omnipresente en las continuas proposiciones callejeras, hechas tanto a mis amigas cubanas como a mí y en las conversaciones con mis amigos, donde se filtraban representaciones en torno a mi sexualidad en tanto que europea. Había dos elementos que me llamaban la atención: el primero, mi imagen como mujer europea, autónoma, independiente, ejemplo de "liberación sexual". Algo paradójico si tenemos en cuenta que la mayoría de mis amigas cubanas tenían, o habían tenido en momentos de su vida, relaciones simultáneas con varias parejas a la vez y se mostraban dispuestas siempre al flirteo, lo cual, aunque podría haber sido, no era mi caso. No obstante, hay que tener en cuenta que funcionaba un doble rasero para medir las relaciones extramatrimoniales: nosotras debíamos mantenerlas en secreto, los varones no. Es decir, ellas, y yo con ellas, debíamos responder a la imagen de "buenas mujeres" que se exigía, algo que yo, me atrevía a desafiar. Una manera de desafiarlo tenía que ver con mis comentarios y actitud hacia esas infidelidades que eran ejemplo de la doble moral de género. Algo que me quedó claro un día que visitamos a unos primos de Adrián en La Habana, donde tomando cerveza en el porche de la casa, ellos empezaron a hablar sobre unos vecinos y de cómo él tenía una amante. Ante eso, y tras mi comentario: "Pues lo que debería hacer ella es echarse un amante también", entre risas comentaron: "Es que las españolas sois muy liberales".

Así, yo sentía que, al ser representada como "no cubana", "liberal", "europea", era definida como portadora de una supuesta sexualidad libre (24) donde se me remarcaba sobre todo el no cumplimiento de los roles asignados en tanto que mujer, una buena mujer cubana, no respetuosa de los límites de género establecidos dentro de las relaciones de pareja: no silenciando las "infidelidades", haciendo expresión explícita de que se tienen otras relaciones sexuales fuera de la pareja, en igualdad con los varones, desafiando "el secreto".

El otro elemento que yo vivía como diferente en relación a mi sexualidad tenía que ver con la supuesta hipersexualización de negros/as y mulatos/as, que se generalizaba a toda la población cubana, frente a la sexualidad más domesticada de los y las turistas, definidos/as como población blanca. En mi caso, al mantener una relación sentimental con un cubano, mulato además, tanto él como yo éramos interrogados por sus amigos acerca de mi supuesta sexualidad pasiva frente a la imagen de la "cubana caliente", al 
tiempo que ensalzaban las habilidades amatorias de todos los cubanos. Un día, hablando Adrián y yo con uno de sus amigos, Carlos, éste nos preguntó directamente por nuestras relaciones sexuales. Según un amigo suyo, al cual se refirió como "jinetero", las mujeres cubanas eran más "calientes" que las turistas y quería saber nuestra opinión, en tanto que cubano y turista. Adrián y yo le respondimos que la actividad sexual tenía más que ver con el deseo que suscita el otro/a que con su origen nacional y que nosotros no habíamos notado diferencias significativas. No obstante, Carlos no se quedó muy conforme, apelando al calor del trópico como uno de los elementos que definen esa supuesta sexualidad irracional, "caliente" de los y las cubanas.

En las personas con las que me relacioné en mi trabajo de campo en República Dominicana apreciaba cómo la sexualidad estaba muy presente, o al menos más de lo que había sido habitual en mis conversaciones fuera de los espacios de intimidad. La sexualidad tampoco parecía tener edad, tan pronto a un niño de meses, no niña, se le ponía a hacer "piquetes" (25), como una anciana se recreaba y hacia movimientos lascivos imaginándose el acto sexual mientras cocinaba. Como me decía una anciana en una ocasión, ninguna mujer se va de este mundo virgen o sin haber tenido relaciones sexuales; si eso ocurre, en el cielo se le echará un burro con un enorme pene erecto. Por mi parte yo percibía que mi sexualidad era imaginada diferente, como si el color de mi piel, lo "blanco", se asociase a pureza, virginidad. En una ocasión, cuando estábamos un grupo de mujeres bañándonos desnudas en el canal en Vicente Noble (26), una mujer exclamó: "¡Mírala si parece una virgencita!”. La visión de mi piel desnuda y más blanca en los lugares donde no me había dado el sol parecía asociarse con virginidad, aunque la creencia acerca de mi virginidad podía estar reforzada por no haber tenido hijos a la edad de 28 años, lo que para ellas era ya una "avanzada edad" en un contexto donde no existe prácticamente separación entre la sexualidad y la procreación, y donde un número elevado de mujeres comienzan su ciclo reproductivo a los 14 y 15 años.

Escuché en muchas ocasiones hablar a las mujeres dominicanas de su sexualidad como un impulso que está casi siempre presente y que es fundamental, puesto que toda mujer ha de experimentar su sexualidad con un hombre. Por el contrario, la sexualidad de "las blancas" se representa como menos voraz y pecaminosa. Esta sexualidad, por otro lado, se significa como un poder de las "negras/dominicanas" frente a las "blancas/españolas", en cuanto a su capacidad de seducir a los hombres españoles, poder que remite a una sexualidad más activa y a una mayor predisposición a realizar ciertas prácticas sexuales para satisfacer a los hombres (27). Un día conversando con una mujer inmigrante, acerca de las infidelidades de su marido mientras ella estaba en España, me explicó que las mujeres de otros campos más pobres (28) están viniendo a Vicente Noble para buscar a los hombres ahora que estaban sus mujeres en España, "ellas les hacen de todo y los enamoran", señalando a continuación que era lo mismo que estaba ocurriendo con las dominicanas en España, que enamoraban a los hombres españoles.

Tanto en República Dominicana como en Cuba, la presencia del "otro", la construcción de las antropólogas como "otras", aparece marcada por elementos que conectan el origen nacional con la sexualidad, la raza y el género. Como mujeres occidentales viajando solas, al igual que algunas turistas, proyectábamos una imagen de modernidad y liberación sexual reforzada en contextos donde se ha generalizado lo que ha venido denominándose turismo sexual (Cabezas 2009 y Alcázar Campos 2010). Y ello al tiempo que nuestra sexualidad era considerada más pasiva, en comparación con la sexualidad de las "otras" mujeres, las negras, portadoras de una sexualidad animalizada "al calor del trópico" o del Caribe.

\section{Para terminar}

Desde nuestra preocupación por la teorización sobre las articulaciones entre las diferenciaciones sociohistóricas de género, raza, sexualidad e inmigración en la construcción de la desigualdad, en este trabajo nos hemos propuesto compartir las diferenciaciones sociales inscritas en nuestros cuerpos, tratando de restituir con ello el valor del saber vivencial, corporizado, implicado y comprometido de la práctica etnográfica. Nuestros trabajos de campo en Cuba y en República Dominicana nos llevan a tomar conciencia de la racialización y sexualización de nuestros cuerpos como antropólogas, contenedores de significados que nos hablan de la decolonialidad (29) y nos interpelan acerca de la reproducción de las relaciones de poder en la práctica etnográfica (Gregorio 2006). En las "zonas de contacto" (Pratt 1992) que hemos habitado, nuestro país o región de procedencia no es un lugar ajeno para las personas con las que nos relacionamos, sino un lugar que el orden económico y geopolítico internacional representa como un lugar de oportunidades, de emigración para encontrar una vida mejor, en definitiva un lugar rico y deseable. Todo ello 
nos sitúa en una relación de poder frente a quienes demandan nuestro capital social y económico, incluso nuestros cuerpos, al tiempo que de incomodidad incluso vulnerabilidad que nos interroga ineludiblemente sobre nuestra práctica etnográfica en un intento de evitar reproducir relaciones de poder decolonial.

\section{Notas}

1. Mi interés por Cuba surge de forma casual, tras un viaje a la isla como turista. Evoluciones posteriores en mi formación antropológica, y el apasionamiento por este país, me llevarían a realizar mi tesis doctoral, con diferentes estancias de investigación entre los años 2004, 2005 y 2009 en Santiago de Cuba y La Habana. Mis inquietudes también se transformaron, pasando de la indagación acerca de los procesos de transformación de las relaciones de género a aquellos elementos que interaccionan para producir relaciones de desigualdad, con el género como uno más, y donde el turismo ocupa un lugar central. Para más información al respecto véase Alcázar 2011 y 2014.

2. Llegué al suroeste de República Dominicana siguiendo a las mujeres que emigraron desde esta región, a finales de los ochenta, a Madrid, para trabajar en el servicio doméstico, en la mayor parte de los casos como internas, y a quienes conocí en un barrio de Madrid (Aravaca) cuando comencé mi trabajo de campo etnográfico para la realización de mi tesis doctoral. Mi convivencia con ellas transcurrió entre diferentes lugares donde se reunían y trabajaban en Madrid y sus diferentes localidades de origen. Más información al respecto puede consultarse en Gregorio 1996 y 1998.

3. El resto del profesorado del departamento que se encargaba de esta asignatura no tenía esta perspectiva teórica, o las cuestiones de género no estaban en el centro de sus preocupaciones.

4. Años más tarde este departamento se disgregaría en dos: Trabajo Social y Antropología Social. Ana Alcázar en la actualidad es profesora ayudante doctora en el departamento de Trabajo Social y Carmen Gregorio es profesora titular en el departamento de Antropología Social.

5. Proyecto "Inmigración y servicio doméstico: estudio acerca del trabajo en el sector servicio doméstico en Granada", financiado por la Junta de Andalucía y llevado a cabo en los años 2003 y 2004 . Véase el trabajo que presentamos en el III Seminario sobre la investigación de la inmigración extranjera en Andalucía celebrado en Huelva y publicado en Gregorio y otros 2003, “¿Muchacha, chacha, una más de la familia? Mujeres inmigrantes en el servicio doméstico en la ciudad de Granada”.

6. Se trató de una comunicación titulada "Mujeres inmigrantes e inserción laboral en el servicio doméstico interno, sus discursos", dentro del III Congreso sobre la Inmigración en España: Contextos y alternativas, que tuvo lugar en el año 2002 en la ciudad de Granada.

7. Para ver el debate que viene suscitando esta denominación, véase el texto de Abu-Lughod (1990) Can There be a Feminist Ethnography?

8. Para la discusión acerca de cómo lo autobiográfico ha sido desconsiderado por las corrientes teóricas dominantes en antropología, véase Gordon 1988, Laslett 1990, Callaway 1992, Okely 1992 y Gregorio 2006. Una vez más nos enfrentamos a la separación entre lo relevante y lo irrelevante a partir del establecimiento de las dicotomías "personal versus teórico", "emocional versus racional", "mujeres antropólogas versus hombres antropólogos". Un primer intento de escribir sobre sus relaciones con las personas en el campo, sobre lo que no escribió en su tesis doctoral, quedando oculto en ese género de escritura que denominamos "diario de campo" bajo la consideración de 'biografía personal', es el trabajo de Gregorio 2002, "Mujer, blanca, española, rica. Trabajo de campo en inmigración y relaciones de género".

9. Un desarrollo de esta manera de entender la antropología como compromiso lo podemos encontrar en Scheper-Hughes 1995. Son interesantes las respuestas controversiales que generó el artículo, publicado en la revista Current Anthropology, suscitando comentarios encendidos, a favor y en contra, de antropólogos/as como Aiwha Ong, Paul Rabinow o Vincent Capranzano.

10. "Laboratorio Iberoamericano para el estudio Sociohistórico de las Sexualidades" dirigido por el profesor 
Jose María Valcuende de la Universidad Pablo Olavide de Sevilla, en el que ambas participamos y desde el que se nos invita a hacer esta contribución para la revista Gazeta de Antropología.

11. En el caso de Carmen Gregorio cabe reseñar sus trabajos sobre la articulación de las diferenciaciones de género, inmigración, extranjería y diferencia cultural a partir de las representaciones de la "mujer inmigrante" en el contexto de la "Fortaleza Europa" (Gregorio 2004, 2010 y 2012). En el caso de Ana Alcázar, sus trabajos sobre la articulación de las diferenciaciones de género, raza, clase social y posición geopolítica que el turismo crea y redefine (Alcázar 2010, 2011 y 2014).

12. En el contexto de los estudios migratorios algunos autores se refieren a ellos como "servicios de proximidad", nosotras preferimos llamarlos así para llamar la atención sobre aquellos trabajos que tradicionalmente han sido realizados por mujeres -el trabajo doméstico y el cuidado a las personas-, fruto de las divisiones de género y parentesco socialmente establecidas en los sistemas capitalistas de producción.

13. Benítez Rojo (1996) usa Plantación, con mayúscula inicial, para referirse al tipo de sociedad que resulta del uso y el abuso de las plantaciones controladas por las potencias europeas en el Caribe. Fueron las potencias europeas las que controlaron la fabricación, el mantenimiento, la tecnología y la reproducción de las máquinas plantaciones, sobre todo en lo que toca al modelo de producir azúcar de caña, dando lugar a una configuración socioeconómica común a todo el Caribe.

14. Se trata de dos de los grupos étnicos y tribales a los que pertenecía la población esclavizada transportada por los negreros desde el continente africano a la isla Cuba.

\section{Expresión cariñosa.}

16. Lugar donde hice la mayor parte de mi trabajo de campo. Esta especificidad de la ciudad de Santiago de Cuba tiene que ver con su pertenencia a la "parte negra", el oriente cubano, y con la rivalidad existente con La Habana, ciudad blanca, de origen burgués y acomodado (pre-revolucionario) y donde la expresión "La Habana es Cuba y el resto es campo" para menospreciar al resto del país era una constante.

17. Palabra de origen taíno para denominar los lugares en los que viven los y las trabajadoras en las explotaciones agrícolas de caña de azúcar (ingenios).

18. Véase esta polémica actuación del gobierno dominicano calificada como "genocidio civil" en http://www.noticiassin.com/2013/09/el-constitucional-ignora-la-corte-interamericana/

19. Aravaca se convirtió en lugar de encuentro para la población dominicana, especialmente la procedente de la Región Suroeste. Este lugar fue conocido en la prensa española por los altercados que provocó la concentración de mujeres dominicanas los jueves y domingos -días para las trabajadoras en el servicio doméstico en régimen de internamiento- y por el lamentable asesinato de una mujer originaria de Vicente Noble, Lucrecia, en una de las viviendas desocupadas de este barrio. Pueden consultarse algunas de las noticias aparecidas en la prensa en el trabajo de Calvo Buezas 1993, "El crimen racista de Aravaca. Crónica de una muerte anunciada". El conflicto social que se dio en este lugar también fue objeto de interés para las antropólogas Nieto y Franzé 1997.

20. Schwartz 1997 y Jayawardena 2003 realizan un análisis del desarrollo del turismo en Cuba en ese contexto pre-revolucionario.

21. Para un desarrollo de estas diferencias de género en torno a la regulación sobre jineterismo, véase Alcázar 2010.

22. En el año 2010 volví a una de las poblaciones, Vicente Noble donde había realizado el trabajo de campo veinte años antes en el marco del proyecto l+D+l (FEM2009-10982) "Etnografiando prácticas de resistencia. Escenarios, eventos y narrativas en la construcción de la ciudadanía".

23. Pratt 1992 denomina "zonas de contacto" a los "espacios sociales donde culturas dispares se encuentran, chocan y se enfrentan, a menudo dentro de relaciones altamente asimétricas de dominación y subordinación, tales como el colonialismo, la esclavitud, o sus consecuencias como se viven en el mundo de hoy" (1992: 31). 
24. Para desarrollar esta idea es interesante el análisis que realiza sobre su trabajo de campo en Grecia la antropóloga Jill Dubisch (1995), según la cual "perdida" y "extranjera" funcionaban casi como sinónimos.

25. Movimiento corporal de la pelvis hacia adelante y hacia atrás simulando el acto de copular.

26. El canal de riego que atravesaba esta población era utilizado por la población para bañarse, dado que muchas viviendas carecían de agua corriente y eran frecuentes las restricciones de agua, como consecuencia de los cortes de luz. Las mujeres nos bañábamos en un lugar y los hombres en otro y normalmente en momentos distintos.

27. Casi siempre se refieren a la felación.

28. La pobreza casi siempre lleva aparejada el color de piel más oscuro, como consecuencia de la segmentación social que existe en este país en términos de clase y color de piel.

29. En el texto utilizamos el término decolonial, en tanto que propuesta teórica formulada desde América Latina (Castro Gómez y Grosfoguel 2007, Mignolo 2000, Quijano 1997) que denuncia el proceso colonial moderno como algo inconcluso. De esta forma, retomamos las críticas que ha recibido la calificación de postcolonial aplicada a las relaciones actuales de dominación que mantiene los antiguos países colonialistas con las excolonias. Esta crítica se refiere, sobre todo, a la existencia misma del prefijo "post", en tanto que prefijo que presentaría las relaciones coloniales como algo superado (Sohat 2008).

\section{Bibliografía}

Abu-Lughod, Lila

1990 "Can there be feminist ethnography?", Women and Performance: A Journal of Feminist Theory, $n^{\circ} 5:$ 7-27.

Alcázar Campos, Ana

2010 "Jineterismo: ¿turismo sexual o uso táctico del sexo?", Revista de antropología social (Madrid), $\mathrm{n}^{\circ}$ 19: 307-336.

2011 La Cuba de verdad. Construcción de desigualdades y turismo en la contemporaneidad. Saarbrüken, Alemania, Editorial Académica Española.

2014 "Relaciones en disputa: nación, género, raza y turismo en Cuba”, Maguaré (Bogotá), vol. 27 (1) (en prensa).

Bell, Diane

1993 "Introduction 1: The Context", en Pat C. Diane Bell y otros (eds.), Gendered fields. Women, men and Ethnography. London, Routledge.

Benítez Rojo, Antonio

1992 La isla que se repite: el Caribe y la perspectiva postmoderna. Madrid, Casiopea.

Cabezas, Amalia.

2009 Economies of Desire. Sex and tourism in Cuba and the Dominican Republic. Philadelphia, Temple University Press.

Callaway, Helen

1992 "Ethnography and experience. Gender implications in fieldwork and texts", en Judith Okely y Helen Callaway (eds.), Anthropology and Autobiography. London, Routledge.

Calvo, Tomás

1993 El crimen racista de Aravaca. Crónica de una muerte anunciada. Madrid, Editorial Popular. 
Castro-Gómez, Santiago (y Ramón Grosfoguel)

2007 El giro decolonial. Reflexiones para una diversidad epistémica más allá del capitalismo global. Bogotá, Siglo del Hombre Editores.

Dubisch, Jill

1995 "Lovers in the field: sex, dominance, and the female anthropologist", en Don Kulick \& Margaret Willson (eds.), Taboo: Sex, identity and erotic subjectivity in anthropological fieldwork. London, Routledge: 29-50.

Foucault, Michel

1978 Vigilar y castigar: nacimiento de la prisión. Madrid, Siglo XXI.

Gordon, Deborah

1988 "Writting culture, writing feminism: the poetics and politics of experimental ethnography", Inscriptions, $\mathrm{n}^{\circ}$ 3/4: 7-24.

Gregorio Gil, Carmen

1996 Sistemas de género y Migración internacional. La emigración dominicana a la Comunidad de Madrid. Madrid, Universidad Autónoma de Madrid.

1998 Migración femenina. Impacto de las migraciones en las relaciones de género. Madrid, Narcea.

2002 "Mujer, española, blanca, rica...: trabajo de campo en inmigración y relaciones de género", en Checa, Francisco (ed.), Las migraciones a debate. De las teorías a las prácticas sociales. Barcelona, Icaria: 315345.

2004 "Entre la inclusión y la exclusión de la ciudadanía: procreadoras, madres y personas", Asparkia. Investigació Feminista, n 15: 11-25.

2006 "Contribuciones feministas a problemas epistemológicos de la disciplina antropológica: Representación y relaciones de poder", AIBR: Revista de Antropología Iberoamericana, vol. 1, nº 1: 22-39.

2010 "Colonizando los cuerpos Fronteras en la representación de las 'mujeres inmigrantes', Cuadernos del Ateneo de la Laguna (La Laguna), n² 28: 47-56.

2011 "Fronteras de género y cultura en el contexto de la "fortaleza europa»", en Dolores Serrano-Niza (coord.), ¿ Visibles o invisibles? Mujeres migrantes, culturas y sociedades. Madrid, Plaza y Valdés: 55-67.

Gregorio Gil, C. (y otros)

2003 "¿Muchacha, chacha, una más de la familia? Mujeres inmigrantes en el servicio doméstico en la ciudad de Granada", en II Seminario sobre la Investigación de la Inmigración Extranjera en Andalucía. Sevilla, Dirección General de Coordinación de Políticas Migratorias: 215-228.

Haraway, Donna J.

1991 Simians, Cyborgs and Women: The Reinvention of Nature. London and New York, Routledge.

Hernández, Jone Miren

2012 "La autoetnografía como habitáculo. Espacios para vivir y compartir", texto inédito presentado en el seminario organizado en el marco del proyecto Etnografiando prácticas de Resistencia. Escenarios, Eventos y Narrativas en la Construcción de la Ciudadanía (FEM2009-10982).

hooks, bell

2005 “Alisando nuestro pelo", La Gaceta de Cuba, n 1: 70-73.

Jayawardena, Chandana

2003 "Revolution to revolution: why is tourism booming in Cuba", International Journal of Contemporary Hospitality Management, vol. 15, $\mathrm{n}^{\circ}$ 1: 52-58.

Laslett, Barbara

1990 "Unfeeling Knowledge: Emotion and Objectivity in the History of Sociology", Sociological Forum, $n^{\circ} 5:$ 413-33. 
Lugones, María

2008 “Colonialidad y género", Tabula Rasa (México DF), n 9: 73-101.

Manderson, Leonore (y M. Jolly) (eds.)

1997 Sites of desire, economies of pleasure: sexualities in Asia and the Pacific. Chicago and London, University of Chicago Press.

Mignolo, Walter D.

2000 Local histories/Global Designs. Coloniality, Subaltern Knowedge and Border Thinking, Princeton University Press, Princeton, 2000.

2009 "Coloniality: The Darker Side of Modernity", en Sabine Breitwisser (ed.), Modernologies. Contemporary Artists Researching Modernity and Modernism Catalog of the Exhibit at the Museum of Modern Art, (catalog of the exhibit Modernologia/Modernologies/Modernology). Barcelona, MACBA: $39-49$.

Moore, Robin Dale

1997 Nationalizing Blackness: Afrocubanismo and Artistic Revolution in Havana 1920-1940. Pittsburgh, University of Pittsburgh Press.

Nieto, Gladys (y Adela Franzé)

1997 "The Projection of Social Conflict Through Urban Space: The Plaza de la Corona Boreal", Current Anthropology, $\mathrm{n}^{\circ} 38$ (3): 461-466.

Okely, Judith

1975 "The Self and Scientism", Journal of the Anthropology Society of Oxford, n 6 (3): 171-88.

1992 "Anthropology and autobiography: participatory experience and embodied knowledge", en Judith Okely y Helen Callaway (eds.), Anthropology and Autobiography. London, Routledge: 1-28.

Ortiz, Fernando

1947 Contrapunteo cubano del tabaco y el azúcar. Madrid, Cátedra, 2010.

Pratt, Mary Louise

1992 Ojos imperiales. Literatura de viajes y transculturación. México D.F., Fondo de Cultura Económica, 2010.

Quijano, Aníbal

1997 "Colonialidad del poder, cultura y conocimiento en América Latina", Anuario Mariateguiano, n 9: 113121.

Scheper-Hughes, Nancy

1983 "The problem of Bias in Andocentric and Feminist Anthropology", Women's Studies, n 10: 109-116.

1995 "The Primacy of the Ethical: Propositions for a Militant Anthropology", Current Anthropology, vol. 36, $\mathrm{n}^{\circ}$ 3: $409-440$.

Schwartz, Rosalie

1997 Pleasure Island: Tourism and Temptation in Cuba. Lincoln, University of Nebraska Press.

Sohat, Ella

2008 "Notas sobre lo postcolonial", en Sandro Mezzadra (comp.), Estudios postcoloniales. Ensayos fundamentales. Madrid, Traficantes de sueños: 103-120.

Stolcke, Verena

1992 Racismo y sexualidad en la Cuba colonial. Madrid, Alianza Editorial.

Strathern, Marilyn

1991 Partial Connections. Savage, Md., Rowman and Littlefield. 
Van Maanen, John

1988 Tales of the Field. On Writing Ethnography. Chicago, The University of Chicago Press.

Gazeta de Antropología 